\title{
Nasopalatine Duct Cyst- A Rare Case Report
}

\author{
Anuna Laila M*, Ambily A and Mahima J \\ Department of Oral Medicine and Radiology, Pushpagiri College of Dental Sciences, \\ India
}

*Corresponding author: Anuna Laila Mathew, Department of Oral Medicine and Radiology, Pushpagiri College of Dental Sciences, Perumthuruthy, Kerala, India, Email: drmathewdan@yahoo.co.in

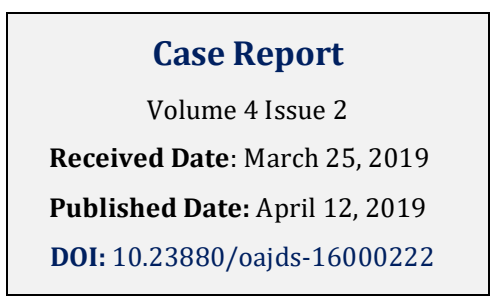

\section{Abstract}

Incisive canal cyst or nasopalatine duct cyst are the most common non odontogenic cysts of the maxilla. These are developmental cysts and are usually asymptomatic, occasionally produces a swelling in the anterior region of the palate and associated pain if secondarily infected. Histopathology shows non-keratinized epithelium with pseudo stratification, ciliation, with neurovascular bundles in the capsular wall. Surgical enucleation of the cyst is the main stay of treatment. Here we report the case of a 16 year old female patient with NPDC.

Keywords: Incisive canal cyst; Nasopalatine duct cyst; Enucleation

\section{Introduction}

Nasopalatine duct cyst was first described by Meyer in 1914. It is one of the most common non odontogenic cysts. It is also termed as incisive canal cyst which arises from the remnants of nasopalatine duct [1-3]. It usually develops in the midline of the anterior maxilla near the incisive foramen [4]. Usually occurs in the fourth to sixth decade of life and men are commonly affected as compared to women [5].

\section{Case Report}

A 16 year old female patient reported to the Department of Oral Medicine and Radiology with the chief complaint of pain and swelling on the upper anterior palatal region of the jaw since 3 days. Patient noticed swelling since 6 months which was initially small in size and has gradually increased to the present size and associated pain since 3 days which was throbbing, continuous in nature and relief reported on intake of analgesics. There was no history of pus or salty discharge from that area, no history of trauma to the upper anteriors. Her medical and family histories were noncontributory.

Extra orally there was no abnormality or lymphadenopathy. On intraoral examination there was an oval well defined swelling $1 \mathrm{x} 1 \mathrm{~cm}$ on the palatal aspect of upper anteriors in the incisive papilla region as shown in (Figure 1). Swelling was soft, non-pulsatile and tender on manipulation. A provisional diagnosis of incisive canal cyst was made. Intraoral periapical radiograph and panoramic radiograph were taken which revealed a welldefined periapical radiolucency measuring around $2 \times 1$ $\mathrm{cm}$ in the periapical region of 11 and 21 with a corticated margin as shown in (Figures $2 \& 3$ ). No radiographic evidence of root resorption or displacement of teeth noted. 


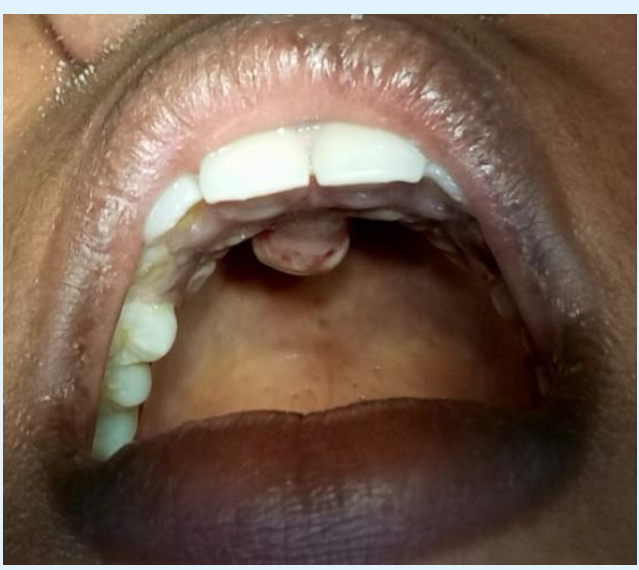

Figure 1: Surface of the swelling showing ulceration.

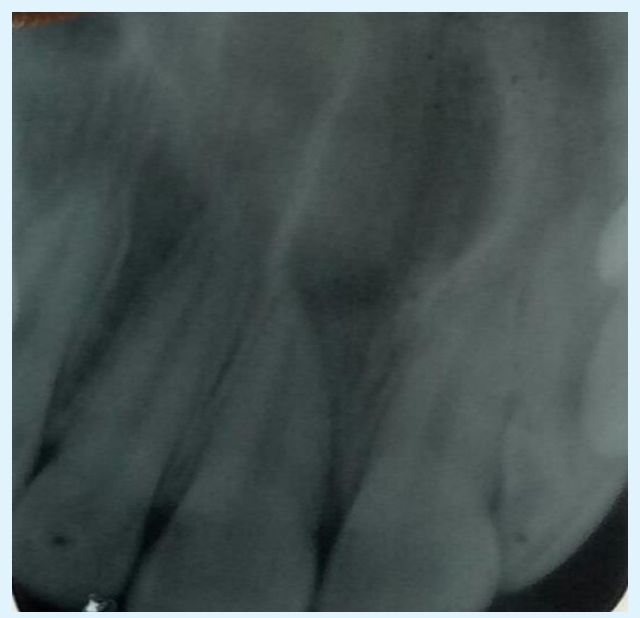

Figure 2: IOPA showing a heart shaped radiolucency between the central incisors.

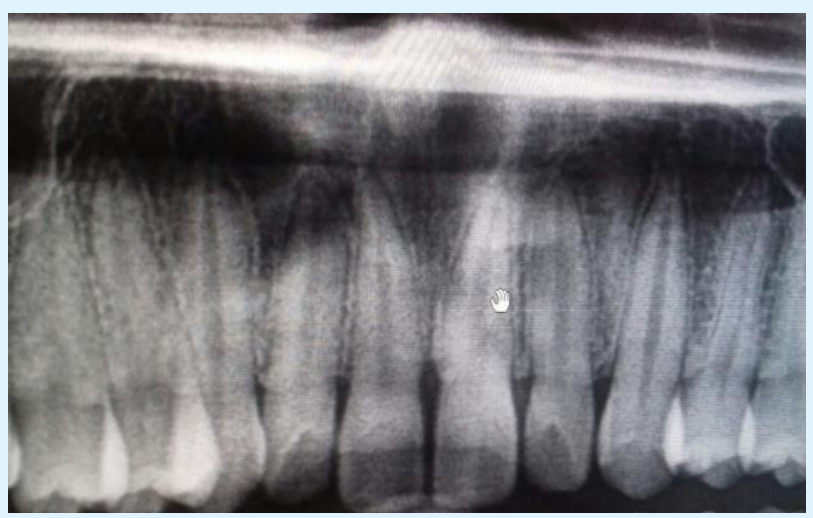

Figure 3: Panoramic radiograph showing heart shaped radiolucency between centrals.

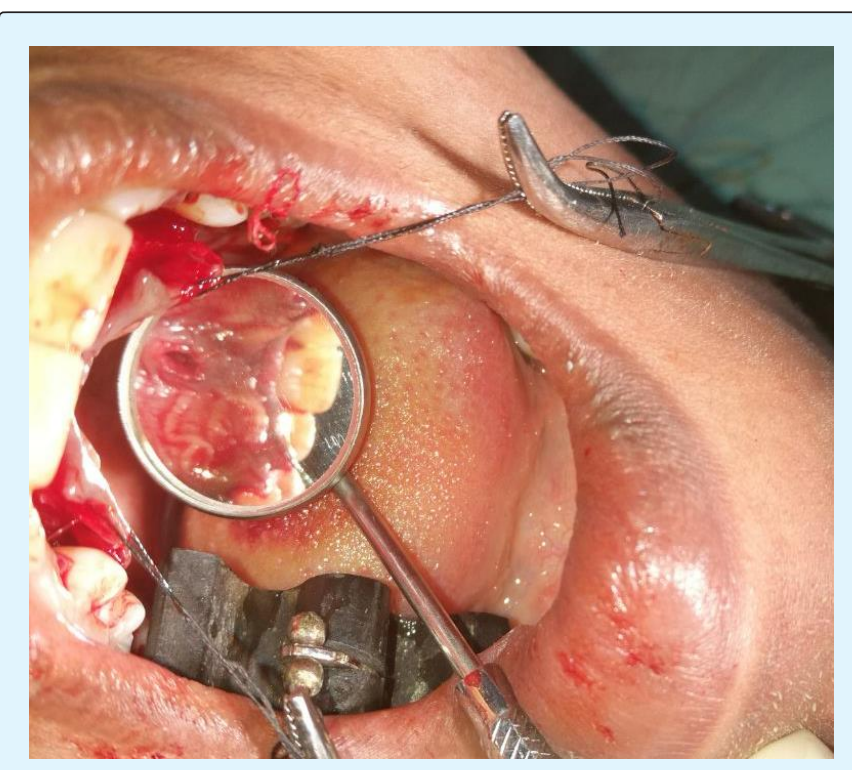

Figure 4: Mucoperiosteal flap reflection of the cyst.

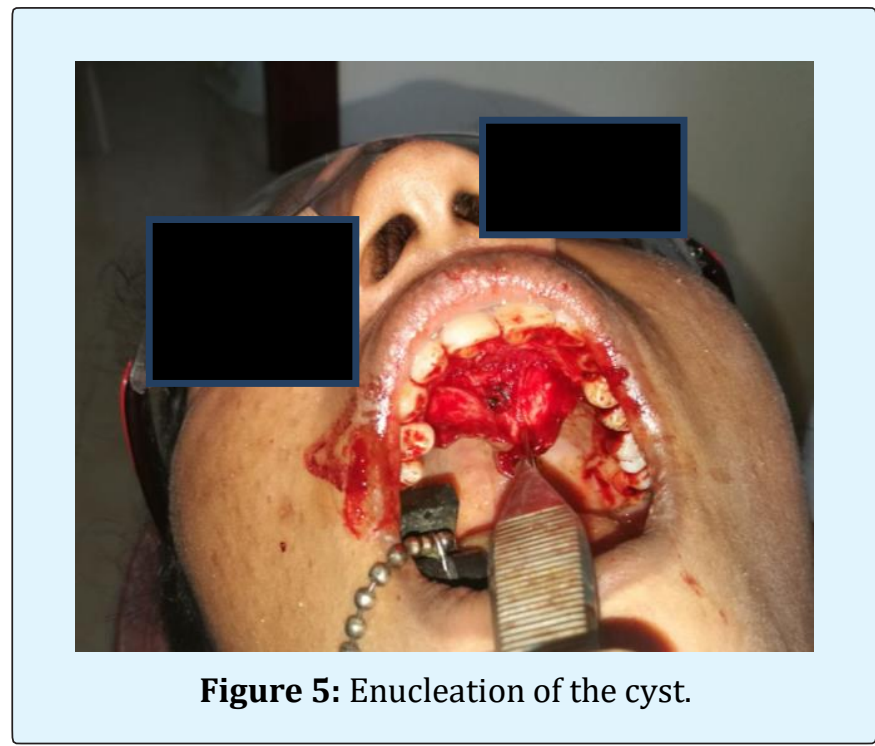

Cyst enucleation was done under LA, by elevating the mucoperiosteal flap and tissue was sent for histopathological examination (Figures 4-6.) $\mathrm{H}$ and $\mathrm{E}$ section showed cystic wall lined by stratified squamous epithelium. Diffuse collection of inflammatory cells are noted in the loose cystic wall. Vasular channels with extravasation of RBCs are also seen suggestive of infected cyst (Figure 7). Post-operative follow up was done and patient is asymptomatic healing is also satisfactory. 

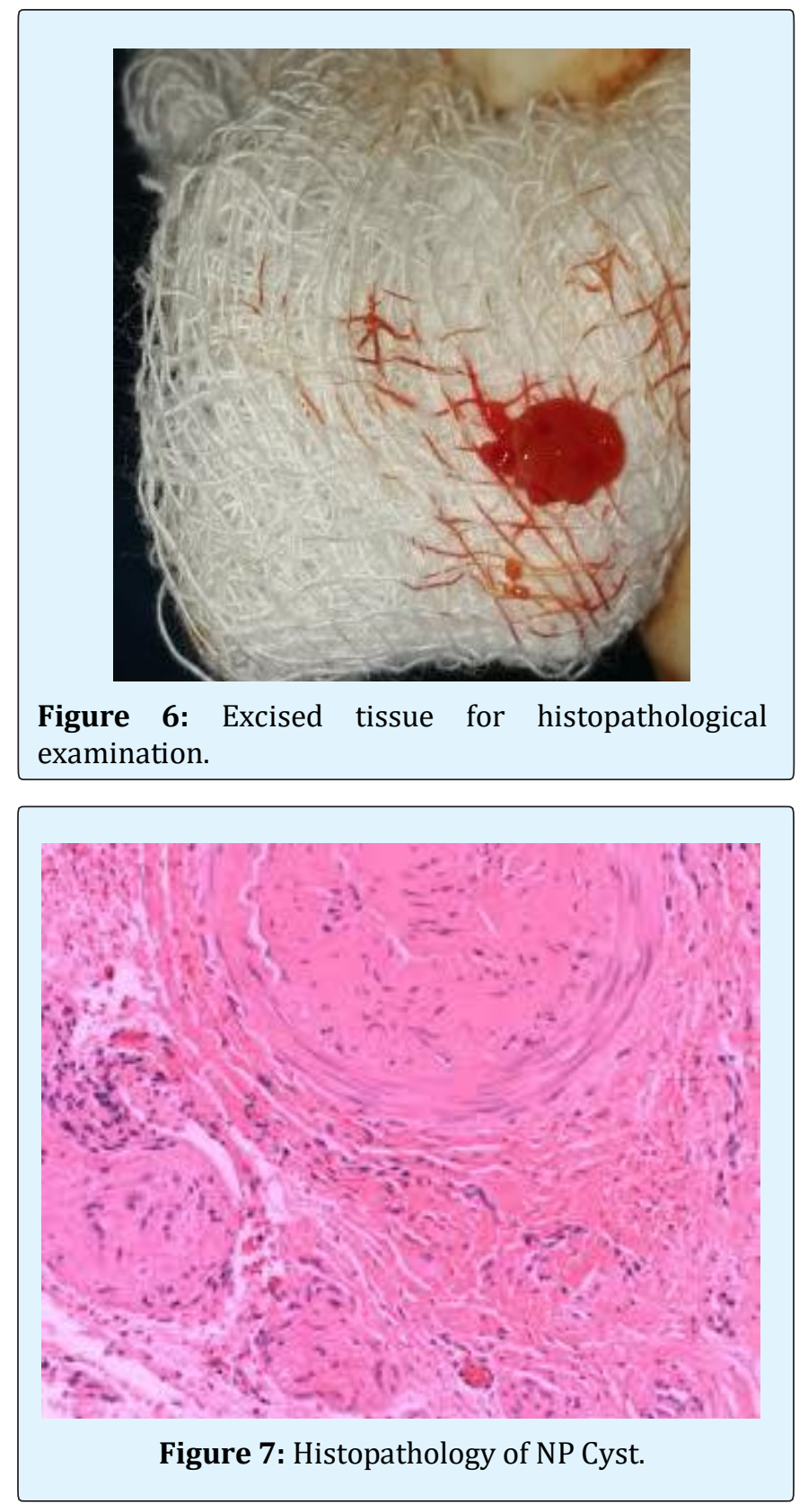

\section{Discussion}

NPDC is a developmental, non odontogenic cyst occurring in the oral cavity [6,7]. It is earlier known as fissural cyst and according to WHO classification it is defined as a non odontogenic, developmental, epithelial cyst of the maxilla. These cyst develop in the midline in the anterior maxilla near the incisive foramen [4]. It usually occurs in the fourth to the sixth decade of life. Men are three times commonly affected than women [5].
The exact etiology is unknown, but trauma, bacterial infection has shown its role in the etiology. It represents around $1 \%$ of the maxillary cysts. Usually it is difficult to distinguish normal incisive canal and foramen from small NPDC that is associated with vital tooth. Radiolucency of the incisive canal region measuring less than $0.6 \mathrm{~cm}$ in diameter should not be considered as cyst in the absence of symptoms [8,9]. Radiographically they are well circumscribed radiolucency that is usually round, ovoid or heart shaped in the anterior maxilla [10].

Histologically NPDC has squamous, columnar, cuboidal or a combination of these epithelium. Epithelium lining depends where the cyst is located. Peripheral nerves, arteries, veins and mucous glands are also noticed [11]. Nasopalatine cysts are usually treated by enucleation, in case of large cysts marsupialization may be considered before enucleation. Recurrence ranges from $0 \%$ to $11 \%$.

\section{Conclusion}

NPDC can occur in approximately $1 \%$ of the population with a peak incidence between fourth and sixth decade of life. The lesions may be asymptomatic, but it may manifest with few symptoms like swelling, pain pus discharge from the anterior hard palate. Radiographically it appears as a well-defined radiolucency in the anterior midline with sclerotic margins. Cyst enucleation is the best treatment plan followed by regular recall visits.

\section{References}

1. Allard RH, van der Kwast WA, van der Waal I (1981) Nasopalatine duct cyst. Review of the literature and report of 22 cases. Int J Oral Surg 10(6): 447-461.

2. Curtin HD, Wolfe P, Gallia L, My M (1984) Unusually large nasopalatine cyst: CT findings. J Comput Assist Tomogr 8(1): 139-42.

3. Sapp J, Eversole L, Wysocki G (2004) Contemporary oral and maxillofacial pathology. $2^{\text {nd }}$ (Edn.), St Louis: Mosby.

4. Damm DD, Lu RJ, Rhoton RC (1988) Concurrent nasopalatine duct cyst and bilateral mesiodens. Oral Surg Oral Med Oral Pathol 65(2): 264-265.

5. Ganasekhar JD, Walvekar SV, al-Kandari AM, alDuwairi Y (1995) Misdiagnosis and mismanagement of a nasopalatine duct cyst and its corrective therapyA case report. Oral Surg Oral Med Oral Pathol Oral Radiol Endod 80(4): 465-470. 


\section{Open Access Journal of Dental Sciences}

6. Salamm ART, Paarthiban V, Gopinath, Karpagam R (2011) Extensive Nasopaltine duct cyst causing Nasolabial Protrusion. Ind J Multidisciplinary Den 1(5): 285-288.

7. Francoli JE, Marques NA, Atyes LB, Escoda CG (2008) Nasopaltine duct cyst: Report of 22 cases and review of literature. Med. Oral Patol Oral Cir Bucal 13(7): 438-443.

8. Basso EC, Paulo Neto ER, Dib LL, Costa C (2012) An unusual case of nasopalatine cyst in Brazilian population. J Health Sci Inst 30: 292-294.
9. Elliott KA, Franzese CB, Pitman KT (2014) Diagnosis and surgical management of nasopalatine duct cysts. Laryngoscope 114(8): 1336-1340.

10. Rajendran R (2012) Developmental Disturbances of Oral and Para oral Structures. In: Rajendran R \& Sivapathasundaram B (Eds.), Shafer's Text book of oral pathology, $7^{\text {th }}$ (Edn.), Reed Elsevier India Private Limited. New Delhi, pp: 64. 